\title{
DNA Methylation Profiling for Diagnosing Undifferentiated Sarcoma with Capicua Transcriptional Receptor (CIC) Alterations
}

\author{
Evelina Miele ${ }^{1, *(\mathbb{D}}$, Rita De Vito ${ }^{2}$, Andrea Ciolfi ${ }^{3}$, Lucia Pedace ${ }^{1}$, Ida Russo ${ }^{1}$, \\ Maria Debora De Pasquale ${ }^{1}{ }^{10}$, Angela Di Giannatale ${ }^{1}$, Alessandro Crocoli ${ }^{4}$, \\ Biagio De Angelis ${ }^{1}$, Marco Tartaglia ${ }^{3}$, Rita Alaggio ${ }^{2}$ and Giuseppe Maria Milano ${ }^{1}$ \\ 1 Department of Pediatric Onco-Hematology and Cell and Gene Therapy, IRCCS Bambino Gesù Children's \\ Hospital, 00165 Rome, Italy; lucia.pedace@opbg.net (L.P.); ida.russo@opbg.net (I.R.); \\ mdebora.depasquale@opbg.net (M.D.D.P.); angela.digiannatale@opbg.net (A.D.G.); \\ biagio.deangelis@opbg.net (B.D.A.); giuseppemaria.milano@opbg.net (G.M.M.) \\ 2 Department of Laboratories, Pathology Unit, IRCCS Bambino Gesù Children's Hospital, 00165 Rome, Italy; \\ rita.devito@opbg.net (R.D.V.); rita.alaggio@opbg.net (R.A.) \\ 3 Genetics and Rare Diseases Research Division, Bambino Gesù Children's Hospital (IRCCS), 00165 Rome, \\ Italy; andrea.ciolfi@opbg.net (A.C.); marco.tartaglia@opbg.net (M.T.) \\ 4 Department of Surgery, IRCCS Bambino Gesù Children's Hospital, 00165 Rome, Italy; \\ alessandro.crocoli@opbg.net \\ * Correspondence: evelina.miele@opbg.net
}

Received: 8 January 2020; Accepted: 3 March 2020; Published: 6 March 2020

check for updates

\begin{abstract}
Undifferentiated soft tissue sarcomas are a group of diagnostically challenging tumors in the pediatric population. Molecular techniques are instrumental for the categorization and differential diagnosis of these tumors. A subgroup of recently identified soft tissue sarcomas with undifferentiated round cell morphology was characterized by Capicua transcriptional receptor (CIC) rearrangements. Recently, an array-based DNA methylation analysis of undifferentiated tumors with small blue round cell histology was shown to provide a highly robust and reproducible approach for precisely classifying this diagnostically challenging group of tumors. We describe the case of an undifferentiated sarcoma of the abdominal wall in a 12-year-old girl. The patient presented with a voluminous mass of the abdominal wall, and multiple micro-nodules in the right lung. The tumor was unclassifiable with current immunohistochemical and molecular approaches. However, DNA methylation profiling allowed us to classify this neoplasia as small blue round cell tumor with CIC alterations. The patient was treated with neoadjuvant chemotherapy followed by complete surgical resection and adjuvant chemotherapy. After 22 months, the patient is disease-free and in good clinical condition. To put our experience in context, we conducted a literature review, analyzing current knowledge and state-of-the-art diagnosis, prognosis, and clinical management of CIC rearranged sarcomas. Our findings further support the use of DNA methylation profiling as an important tool to improve diagnosis of non-Ewing small round cell tumors.
\end{abstract}

Keywords: undifferentiated sarcoma; DNA methylation profiling; CIC alteration; diagnosis

\section{Introduction}

Primitive small blue round cell tumors (SBRCTs) in children and young adults pose a diagnostic challenge. Ewing sarcoma (ES) is the prototype for an undifferentiated sarcoma with such a phenotype, although it is shared by several other sarcoma entities together with the membrane expression of CD99 [1,2]. An advance in the diagnosis of Ewing's sarcoma was the discovery 
of recurrent, highly-specific balanced translocations leading to a chimeric gene fusion involving the RNA-binding TET (translocated in liposarcoma/Ewing sarcoma breakpoint region 1/TATA box binding protein-associated factor) gene family members, mainly EWSR1, and members of the E26 transformation-specific (ETS) gene family. EWSR1-FLI1 or EWSR1-ERG are the most common translocations in ES and are observed in $~ 85 \%-90 \%$ and $5 \%-10 \%$ of all cases, respectively [3,4]. Far rarer are other gene fusions involving different TET (FUS) and ETS family members (ETV1/4, FEV, and $E 1 A-F)$ and rearrangements of EWSR1 with non-ETS family genes (including NFATc2, PATZ1, SMARCA5, and SP3), which occur in fewer than $1 \%$ of ES [5-10].

Molecular techniques, including extended Fluorescent in situ hybridization (FISH) analysis and next generation sequencing, have allowed the separation of ES with canonical translocations from a subset of lesions that remains unclassified. These are termed "Ewing-like sarcomas", or SBRCTs not otherwise specified in the last World Health Organization classification [11,12]. Although a number of SBRCTs remains unclassified, emerging molecular evidence, most notably transcriptome analysis, has helped to distinguish previously unrecognized tumor entities that many investigators now consider as distinct from ES [2,13]. These are Ewing-like sarcomas most commonly harboring CIC and BCL6 Corepressor $(B C O R)$ rearrangements $[1,2,14-17]$. CIC rearranged sarcomas arise more often in soft tissues rather than in bone, show a myxoid matrix, have prominent nucleoli, and are characterized by a poor prognosis, especially for patients with metastatic or recurrent disease [1,2].

Diagnosis of such tumors is difficult due to their rarity and unspecific histological features but is possible by combining morphological, immunohistochemical, and molecular techniques [1,2]. However, FISH and total RNA sequencing may sometimes have pitfalls in identifying some rearrangements. Koelsche and colleagues recently introduced array-based DNA methylation profiling as a method with extraordinary power for clarifying the diagnoses of a cohort of tumors initially deemed SRBCT not otherwise specified [12].

Here we report a challenging diagnosis of undifferentiated sarcoma with CIC alteration identified with DNA methylation profiling. To further inform management of such cases, we review the available literature and discuss the current knowledge on molecular and clinical features of $C I C$ rearranged sarcomas. We conclude that DNA-methylation-based tumor classification can be an important tool in advancing the diagnosis, pathological analysis, and management of these tumors.

\section{Case Report}

A 12-year-old female was referred to our hospital emergency department with recent-onset abdominal pain. No other symptoms were recorded; she had no fever, vomiting or diarrhea. Diuresis and menstrual cycle were regular as well. Clinical examination revealed a hard-elastic swelling in the meso-hypogastric region. Complete abdomen ultrasound and magnetic resonance imaging (MRI) showed a voluminous bilobed mass of approximately $13.5 \mathrm{~cm} \times 7 \mathrm{~cm}$, with regular margins, in the left paramedian of the anterior abdominal wall, extending from the umbilical region to the supra-bladder area and, posteriorly reaching the spinal vertebral bodies at the lumbar-sacral level. The cranial portion of the mass appeared capsulated with signal over-intensity in all impulse sequences in relation to myxoid component and high cellularity in diffusion weighted imaging (DWI). The caudal portion appeared more inhomogeneous, predominantly hypo-intense in all sequences, as for bleeding (Figure 1A-G).

An incisional biopsy of the tumor was performed. Histological examination showed proliferation of medium-sized elements, with sharp cellular contours, dimly eosinophilic cytoplasm, and polymorphic and polymetric nuclei, with evident nucleoli and atypical mitotic figures (Figure 2A-C). The cells appeared immersed in amorphous, dimly eosinophilic proteinaceous material. Hemorrhagic extravasation in the interstitium was observed. Immunohistochemical characterization was as follows: Vimentin: positive; S100: rare positive cells; CD99 (Figure 2D) and CD31: weak positivity; Neuron Specific Enolase (NSE): weak positivity; Cytokeratin (CK) MNF116: rare positive cells;CKAE1-AE3: rare positive cells; CD117: weak positivity; Friend leukemia integration 1 transcription factor (FLI1): positive; 
Wilms' tumor (WT1): positive (Figure 2F), nuclear; INI: positive; Bcl6: weak positivity; Transducin-like enhancer of split 1 (TLE1): positive Epithelial membrane antigen(EMA), Synaptophysin, Actins, CK7, Desmin, Myogenin, MyoD, Leukocyte common antigen (LCA), CD30, Activin receptor-like kinase (ALK1), Myeloperoxidase (MPO), Terminal deoxynucleotidyl transferase (TdT), Melanoma-associated antigen recognized by T cells (MART1), CD34, p63, NUT, CD56, Placental alkaline phosphatase (PLAP) were all negative. The proliferation index evaluated through Ki-67 assay was high (Figure 2E).

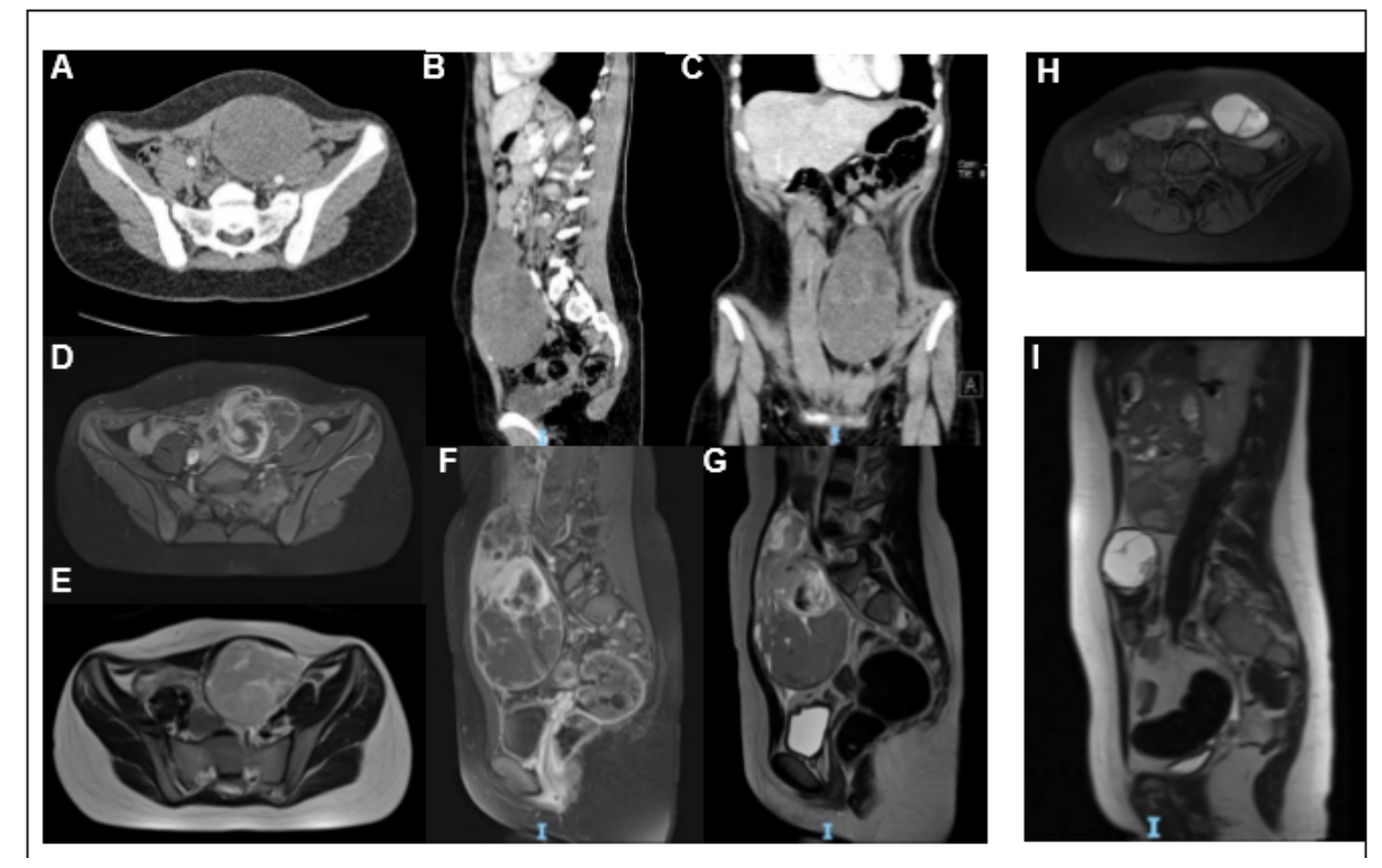

Figure 1. Imaging: Axial (A), sagittal (B), and coronal (C) Computed tomography (CT) scan images showing a gross expansive non-infiltrating mass, with clear and well-defined margins and an oval and oblong appearance. In coronal sections, it clearly shows a bilobated aspect with a homogeneously hypodense apical portion and a well-capped lower portion, which has a more uneven density, as in fluid internal lacunae. The lesion has a maximum size of $81.9 \mathrm{~mm} \times 77 \mathrm{~mm}$ and a deep cranium-caudal extension of approximately $14 \mathrm{~cm}$, up to the pelvic floor and posterior to the lumbosacral spine, which appears to have a cleavage plane. Magnetic resonance imaging (MRI) images (D-I) of the expansive process at diagnosis (D-G) and after neoadjuvant chemotherapy (H-I). T1w-fat sat axial (D) and sagittal (F), T2w axial (E) and sagittal (G) images show a heterogeneous mass extending in the left abdominal wall, in the left paramedian seat at the level of the navel. T1w-fat sat axial images (H) and $\mathrm{T} 2 \mathrm{w}$ sagittal (I) images show a clear reduction in the dimensions of the known expansive formation after chemotherapy.

Molecular evaluation by both FISH and PCR found no evidence of the translocation of EWS. PCR testing for CIC-DUX4, BCOR-CCNB3, and for the myxoid chondrosarcoma transcript was also negative. Histopathological diagnosis was determined through examination of the specimen at the Italian pediatric sarcoma central pathology panel whose conclusion was a malignant mesenchymal neoplasm/unclassifiable sarcoma. 


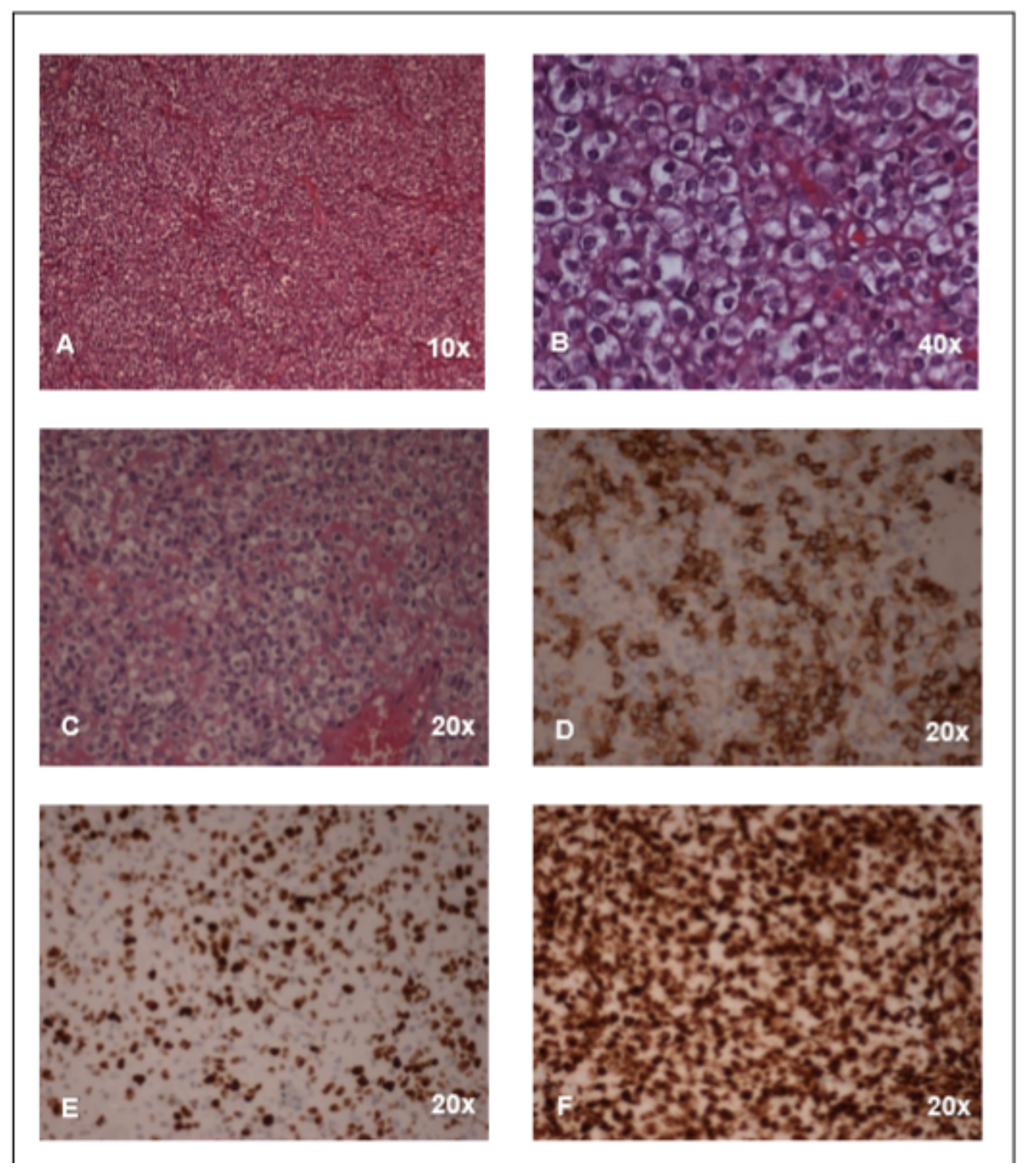

Figure 2. Histology: (A-C) Representative images (hematoxylin/eosin staining) of the malignant undifferentiated mesenchymal neoplasia. The cells were mostly epithelioid with clear cytoplasm in a solid pattern. (D-F) Immunostaining for CD99 (D), Ki67 (E), and WT1 (F).

To complete the diagnostic work-up, the patient underwent bone scintigraphy, which was negative for areas of abnormal accumulation. A Positron Emission Tomography (PET)/CT scan confirmed the presence of the mass, which was metabolically active (maximum standardized uptake value -SUV 7 and diameter $14 \times 8.2 \times 7.7 \mathrm{~cm}$ ) at the left rectus abdominis muscle, with extensive development in the meso- and hypo-gastric site. Compressive phenomena in some loops of the small bowel and on the left psoas muscle were also observed. The tumor was capsulated without infiltration of the surrounding structures. There were no other areas of tracer uptake in the peritoneum, lymph nodes, lungs, and skeletal segments. A CT scan showed millimetric nodules in the latero-basal segment of the lower lobe of the right lung, in the dorsal segment of the upper lobe of the right lung in the sub-pleural area, and in the middle lobe, where metabolic activity could not be assessed due to the small size of the nodules.

DNA methylation profiling was performed according to protocols approved by the institutional review board, after obtaining written consent from the patient's parents. Tumor areas with the highest tumor cell content $(\geq 70 \%)$ were selected for DNA extraction. Samples were analyzed using Illumina Infinium Human Methylation EPIC Bead Chip (EPIC) (Illumina, San Diego, CA, USA) arrays according to the manufacturer's instructions, as previously reported [18-20]. In detail, 500 ng DNA were used as input material for fresh frozen tissue. Generated methylation data were compared with the Heidelberg 
sarcoma classifier [21] to assign a subgroup score for the tumor compared to 63 different sarcoma methylation classes identified to date.

The tumor had a score of 0.98 in the "methylation class SRBCT with CIC alteration". Global profiling methylation data were also compared to 32 samples randomly extracted from internal and external datasets [21] among those classifying as central nervous system neuroblastoma FOXR2 (CNS-NB-FOXR2), CIC rearranged sarcoma (EFT-CIC), high-grade neuroepithelial tumor MN1 (HGNET-MN1), and high-grade neuroepithelial tumor BCOR (HGNET-BCOR) using the Heidelberg brain tumor and sarcoma classifier. Bead Chip data were analyzed by means of $R$ (V. 3.4.4) package minfi (V. 1.24.0) to obtain normalized beta values and to perform multidimensional scaling (MDS) analysis, as previously described [18-20]. Our patient displayed global methylation levels close to those of Ewing Family Tumor (EFT)-CIC, as evidenced by MDS performed on the 1000 most variable islands in the cohort (Figure 3). The copy number variation plot showed a segmental loss on chromosome arm $1 p$, a deletion in $4 q$, and a duplication of $20 q$ (Figure 4). These results were also confirmed by chromosomal microarray analysis, which showed the following three somatically acquired defects: $40.1 \mathrm{Mb}$ deletion in 1p36.33p34.2; 1.3 microdeletion $\mathrm{Mb}$ in 4q35.2; $1.1 \mathrm{Mb}$ microduplication in 20q13.2.

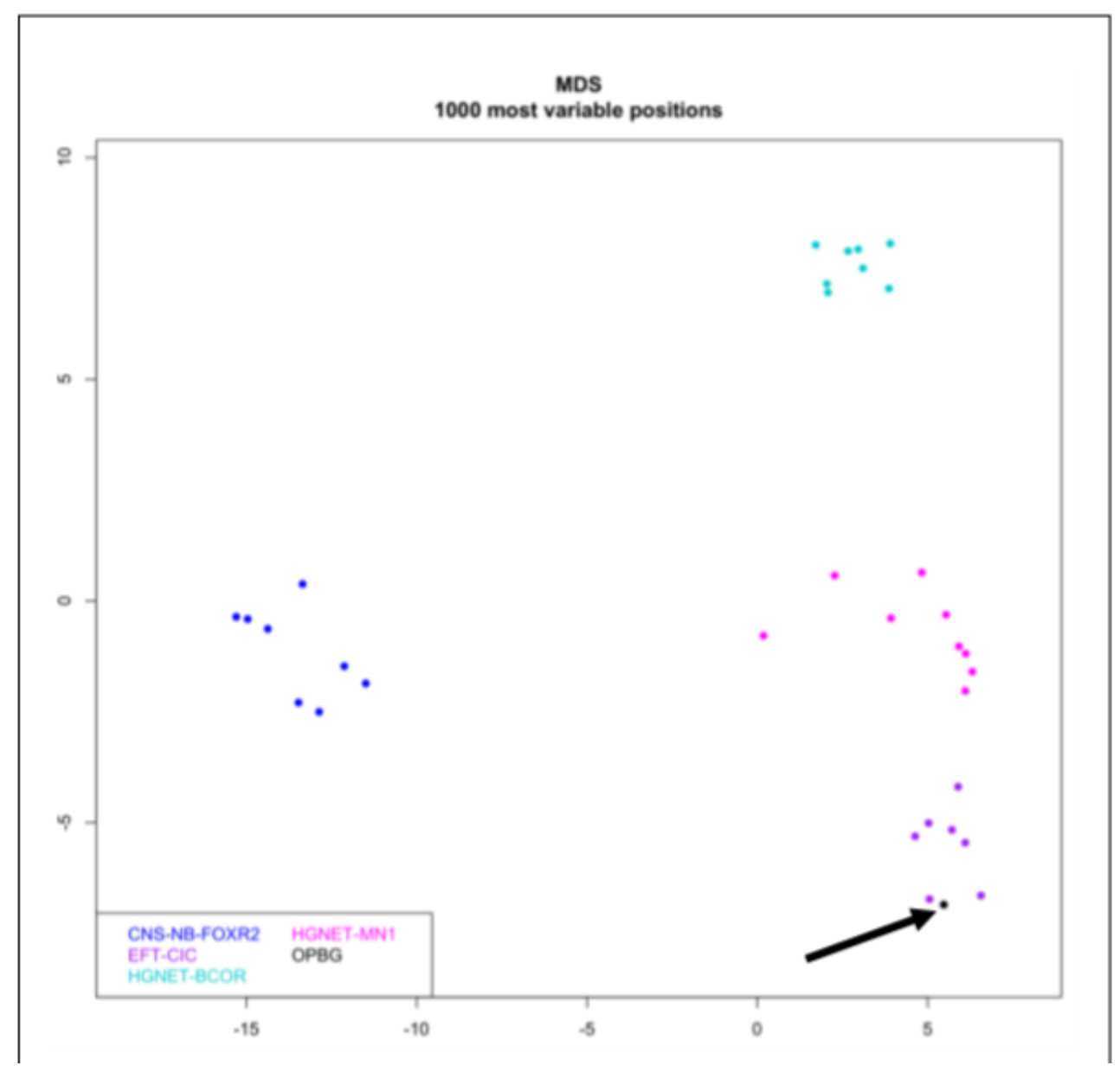

Figure 3. Multidimensional scaling (MDS) analysis performed on the 1000 most variable probes of the whole genome DNA methylation data shows a close similarity between the present case (OPBG) and CIC rearranged sarcomas, while clearly separate from other tumor entities. Color legend of the MDS plot as follows: CIC rearranged sarcoma case (black and arrowed); central nervous system neuroblastoma FOXR2 (CNS-NB-FOXR2) (blue); EFT-CIC (violet); high-grade neuroepithelial tumor-MN1 (HGNET-MN1) (pink); high-grade neuroepithelial tumor BCOR (HGNET-BCOR) (cyan). 


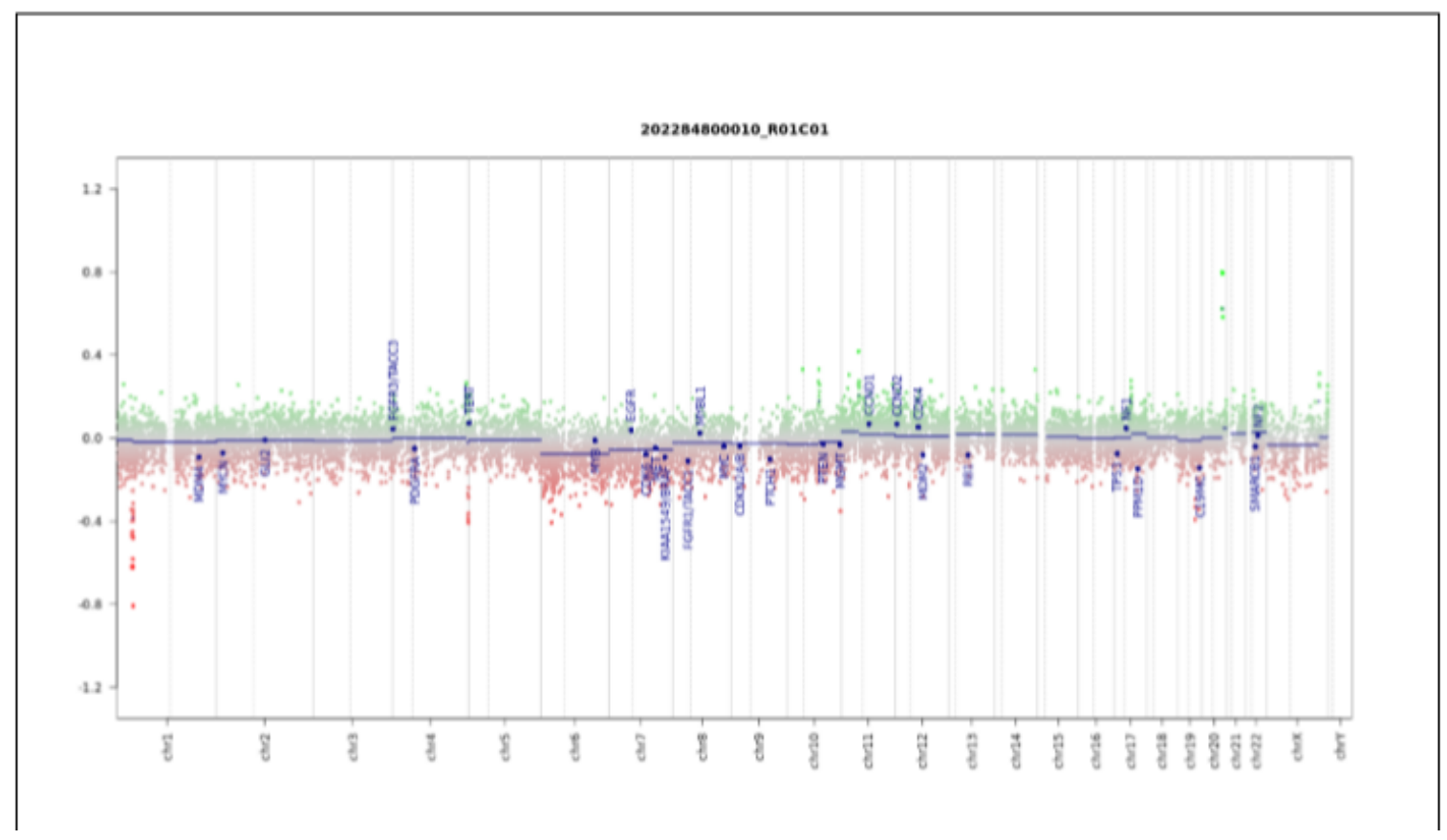

Figure 4. Copy number variation (CNC) profile analysis. Depiction of structural rearrangements involving autosomes and X/Y chromosome. Gains/amplifications represent positive (green) and losses represent negative (red) deviations from the baseline. Twenty-nine tumor relevant genomic regions are highlighted.

In light of the histological, molecular, and clinical findings, a neoadjuvant chemotherapy was proposed to the patient's family. After written informed consent was obtained, neoadjuvant chemotherapy was started according to European Pediatric Soft Tissue Sarcoma Study Group (EpSSG) 2005 non-Rhabdomyosarcoma protocol (Intergroup Rhabdomyosarcoma Study-IRS stage III). After three cycles of ifosfamide ( $3 \mathrm{gr} / \mathrm{m}^{2} /$ day for three days) and doxorubicin $\left(37.5 \mathrm{mg} / \mathrm{m}^{2} /\right.$ day for 2 days) every three weeks, disease reevaluation showed an excellent response, with shrinkage of tumor volume $(8.1 \times 5.6 \times 3.9 \mathrm{~cm})$ (Figure 1H,I). The pulmonary nodules remained stable.

A gross total resection of the residual tumor was performed. Histological examination showed a reactive fibrous pseudocapsule surrounding the mass peripherally. Regression areas, alternating with vital areas were observed. The regression areas, which were quantified in about $60 \%$ of the total mass, showed evidence of necrosis, hemorrhagic infarction, and histiocytic infiltration by elements with a foamy and/or pigmented aspect due to the presence of abundant hemosiderin in the interstice. The vital areas were irregularly distributed within the mass and quantified in about $40 \%$ of the total. They consisted of elements with a morphology and immunohistochemical pattern substantially similar to the one detected in the diagnostic biopsy. The margins of resection were negative.

Three cycles of adjuvant chemotherapy were administered: two of ifosfamide $\left(3 \mathrm{gr} / \mathrm{m}^{2} /\right.$ day for two days), one of ifosfamide ( $3 \mathrm{gr} / \mathrm{m}^{2} /$ day for three days), and doxorubicin $\left(37.5 \mathrm{mg} / \mathrm{m}^{2} /\right.$ day for 2 days) every three weeks. At the 22-month follow up, the patient was in good clinical conditions and disease free.

While the revision of this manuscript was ongoing, we further analyzed the case by next generation sequencing (Archer FusionPlex Sarcoma kit -ArcherDX, Boulder, CO, USA) and finally detected the CIC-DUX4 rearrangement: CIC (Exon20) $\rightarrow$ DUX4 (Exon1), confirming the results obtained by methylation profiling (Supplementary Figure S1). Total RNA was extracted from 5 to $10 \mu \mathrm{m}$ formalin-fixed paraffin-embedded (FFPE) tissue sections using the Qiagen miRNeasy FFPE kit (Qiagen, Valencia, CA, USA), quantified by using Qubit fluorimeter (Thermo Fisher Scientific, Waltham, MA, USA) and quality checked on the 2100 Bioanalyzer by using the RNA 6000 Nano kit (Agilent Technologies, Santa Clara, CA, USA). Anchored multiplex PCR-based libraries were prepared and 
run on Illumina (Miseq, San Diego, CA, USA) platforms according to the manufacturer's instructions. The Archer Analysis bioinformatics platform was exploited for the analysis of the Archer FusionPlex panel results.

\section{Discussion}

CIC rearranged sarcomas are rare but represent the most frequent molecular subtype among Ewing-like undifferentiated SBRCTs [1,22], accounting for approximately $70 \%$ of SBRCTs lacking EWSR and FUS rearrangements [2,16,23-25]. CIC rearranged tumors are characterized by fusions involving CIC, a human homolog of Drosophila Capicua located on chromosome 19q13.2 and encoding a transcriptional repressor, functioning downstream of tyrosine kinase receptor signaling.

The first case of a CIC rearranged round cell sarcoma with $\mathrm{t}(4 ; 19)(\mathrm{q} 35 ; \mathrm{q} 13.1)$ translocation was reported in 1996 in a 12-year-old male with an ankle mass and pulmonary metastases [26,27]. In 2006, Kawamura-Saito et al. [14] identified the molecular feature characterizing these tumors-the CIC-DUX4 (double-homeobox 4) chimeric protein resulting from this translocation in a report of two adult patients. The CIC-DUX4 fusion most often results from either $\mathrm{t}(4 ; 19$ (q35; $\mathrm{q} 13)$ or, less frequently, from $\mathrm{t}(10 ; 19)(\mathrm{q} 26 ; \mathrm{q} 13)$, the latter involving the DUX4 paralog DUX4L.

Both DUX4 and DUX4L genes contain a 3.3-kb tandem repeat sequence located in the sub-telomeric regions of the long arms of chromosomes 4 and 10, respectively [28]. They encode for double-homeobox transcription factor typically expressed in germ cells as well as in the human testis, but epigenetically silenced by methylation in differentiated cells [1,29-31]. No significant clinical-pathologic differences have been reported between tumors harboring the $t(4 ; 19)$ versus the $t(10 ; 19)$ [31]. The CIC-DUX4 chimeric protein generally shows a largely preserved CIC domain, including the high mobility group box, fused in-frame with the C-terminus of DUX4/L, which loses most of its sequence in the fusion [32]. Such genetic rearrangement increases the transcriptional activity of CIC. The deriving chimeric protein is an oncogenic transcription factor that dysregulates the expression of its downstream targets [16]. In particular, the biological consequence is an upregulated expression of genes normally repressed by CIC, including polyoma enhancer activator 3 (PEA3) family members of ETS-related transcription factors ETV1, ETV4, and ETV5 [14,16,24,33]. Of note, PEA3 belongs to the family of ETS-related transcription factors reported as rare fusion partners of EWSR1 in ES [22,34,35].

Even if DUX4 is the most common partner gene of CIC [16,22], SBRCTs with alternate fusion partners of CIC have also been described. These include FOXO4 [36,37] and NUT midline carcinoma family member 1 (NUTM1) [38] and occasionally other still-uncharacterized partner genes [25,31,36,37]. This variability of the CIC gene fusions has prompted the use of the term "CIC rearranged family of tumors" [25] to include alternate fusion partners under the definition of the entity [2]. Indeed, gene expression profiles of these tumors cluster tightly with CIC-DUX4 and CIC-DUX4L rearranged tumors [25,37]. Conversely, transcriptomes of CIC-DUX4 fusion and other CIC rearranged sarcomas compared with ES family of tumors (ESFTs) with EWSR1-ETS fusions show little overlap in differentially expressed genes, supporting the distinction of these tumors from ESFTs [2].

Further evidence to support CIC rearranged sarcomas as a distinct entity was seen in experiments conducted by Yoshimoto et al. [33]. The authors generated a mouse model expressing the human CIC-DUX4 fusion gene (mCDS) and compared the gene expression profile of the mCDS mutant mice with that of mice with classic ES (mES). They found a large number (1661) of differentially expressed genes in $\mathrm{mCDS}$ or $\mathrm{mES}$, suggesting that CIC-DUX4 sarcomas are distinct from ES. Moreover, CIC rearranged sarcomas have been reported to show specific epigenetic signature (as discussed below) [12].

From a clinical point of view, CIC rearranged SRBCTs affect a wide age range (6-81 years), but are diagnosed most frequently in young adults (mean age 30 years, slightly more predominant among males) $[16,31,39]$. Approximately $90 \%$ of these tumors arise in soft tissues, evenly divided between trunk/pelvis and extremities and only rarely in visceral organs (around $10 \%)$ or bone $(<5 \%)[2,16,31,39]$. There are no known associated risk factors [2]. 
Although there are limited clinical data to date, these tumors seem to have a significantly more aggressive course when compared with classic ES [16,31,33]. In particular, in the largest series reported to date, Antonescu et al. compared the clinical follow-up of 45 patients affected by CIC rearranged sarcoma with localized disease with a control group of 45 ES cases, showing a $43 \% 5$-year survival versus $77 \%$ of ES [31]. Smaller series reported similar results $[25,40,41]$ with a median survival less than two years, despite a multimodal therapeutic approach (surgery and/or chemotherapy/and or radiotherapy) [41]. Indeed, contrary to ES, where the traditional therapeutic strategy is the neo-adjuvant chemotherapy due to the strong tumor chemo-responsiveness, responses to neoadjuvant chemotherapy in most CIC rearranged sarcoma patients were minimal or generally temporary with rapid onset of drug resistance and disease progression $[25,40,41]$. In contrast to these findings, our patient showed a dramatic response to neoadjuvant chemotherapy and, although follow-up is limited, remains disease free. Most of the data available on chemotherapy response in CIC rearranged sarcoma patients refer to the older population, so the discrepancy between our patient response and the literature report could be found in the young age of our patient.

The optimal therapeutic approach for CIC rearranged sarcoma patients remains to be defined [1,2,42], pending the results of clinical trials or meta-analyses from multi-institutional data.

No specific radiological and gross features have been reported thus far. Tumors are often extensively hemorrhagic and necrotic. MRI studies of CIC rearranged sarcomas usually show tumor originating from the deep soft tissues of the trunk, pelvis, or proximal extremities with heterogeneous but intense post-contrast enhancement [2], as in the present case.

Microscopically, CIC rearranged sarcomas are characterized by a more heterogeneous appearance than usual ES. They more frequently show "atypical features", including plasmacytoid and rhabdoid features in approximately $25 \%$ and spindling in about $10 \%$. They also show greater nuclear pleomorphism $[16,31,32,39,43]$ with scant cytoplasm and prominent nucleoli, the latter being a useful initial diagnostic clue [2,44]. Myxoid stromal changes mimicking high-grade extra-skeletal myxoid chondrosarcoma or myoepithelial carcinoma are reported in some case [25,31]. They completely lack evidence of neuroectodermal differentiation, as Homer Wright rosettes that can be present in ES [2]. Mitotic rates are high, with almost all cases showing $>10$ mitotic figures per 10 high power fields [2,31]. Areas of necrosis are commonly observed (Table 1) [31,45].

Immunohistochemically, CIC rearranged sarcomas have been reported to show a unique expression pattern from ES (see Table 1 readapted from [2]). Up to $75 \%$ of cases co-express membrane CD99, usually focal and patchy, unlike the diffuse pattern observed in classical ES, and nuclear WT1 $[2,17,22,46]$. The vast majority of CIC-DUX4 sarcomas express ERG and FLI1, as frequently as in classic ES [22], representing an important diagnostic challenge in differential diagnosis. CIC rearranged sarcomas often express diffuse nuclear ETV4, [46,47]. On the contrary, ES, BCOR rearranged sarcoma, and poorly differentiated synovial sarcomas, are negative for both nuclear ETV4 and WT1 staining $[2,46]$. Of note, nuclear WT1 positivity is also found in desmoplastic small round cell tumor and Wilms tumor, which should be considered in morphologic differential diagnosis [2]. The downstream target of EWSR1-FLI1, NKX2-2, is expressed in virtually all ES but is negative in CIC rearranged sarcomas $[2,25,48]$. Diffuse MYC immunohistochemical staining has been shown to be highly specific, detectable in 10 out of 10 cases of CIC-DUX sarcomas [45]. CIC rearranged sarcomas could also have positivity for calretinin, thus overlapping with mesothelioma [25]. A small number of cases can express focal desmin and cytokeratin AE1/AE3 (approximately $15 \%$ and $4 \%$, respectively) [31]. 
Table 1. Differential diagnosis of round cell sarcomas (readapted [2]).

\begin{tabular}{|c|c|c|c|c|c|c|c|c|}
\hline & $\begin{array}{l}\text { CIC-Rearranged } \\
\text { Sarcoma }\end{array}$ & $\begin{array}{l}\text { BCOR-Rearranged } \\
\text { Sarcoma }\end{array}$ & Ewing Sarcoma & $\begin{array}{c}\text { Poorly } \\
\text { Differentiated } \\
\text { Synovial } \\
\text { Sarcoma }\end{array}$ & $\begin{array}{c}\text { Desmoplastic } \\
\text { Small Round } \\
\text { Cell Tumor }\end{array}$ & $\begin{array}{c}\text { Alveolar } \\
\text { Rhabdomyosarcoma }\end{array}$ & $\begin{array}{l}\text { Mesenchymal } \\
\text { Chondrosarcoma }\end{array}$ & $\begin{array}{l}\text { High-Grade } \\
\text { Myxoid } \\
\text { Liposarcoma }\end{array}$ \\
\hline Peak incidence & 3rd-4th decade & 2nd decade & 2nd decade & 4th decade & 3rd decade & 2nd decade & 3rd decade & 4th decade \\
\hline $\begin{array}{l}\text { Most common } \\
\text { anatomic site }\end{array}$ & $\begin{array}{l}\text { Soft tissues of } \\
\text { trunk/pelvis and } \\
\text { extremities }\end{array}$ & $\begin{array}{l}\text { Pelvic bones and } \\
\text { metadiaphysis of } \\
\text { long bones of lower } \\
\text { extremities }\end{array}$ & $\begin{array}{l}\text { Metadiaphysis } \\
\text { of long bones, } \\
\text { ribs, pelvis }\end{array}$ & $\begin{array}{l}\text { Soft tissues of } \\
\text { extremities }\end{array}$ & $\begin{array}{l}\text { Soft tissues and } \\
\text { viscera of } \\
\text { abdomen }\end{array}$ & $\begin{array}{c}\text { Soft tissues of } \\
\text { extremities }\end{array}$ & $\begin{array}{l}\text { Facial bones, long } \\
\text { bones of lower } \\
\text { extremities, and } \\
\text { pelvic bones }\end{array}$ & $\begin{array}{l}\text { Soft tissues of } \\
\text { lower limbs, } \\
\text { especially } \\
\text { thigh }\end{array}$ \\
\hline Cytomorphology & $\begin{array}{l}\text { Round cells with } \\
\text { moderate } \\
\text { eosinophilic } \\
\text { cytoplasm }\end{array}$ & & $\begin{array}{l}\text { Monotonous } \\
\text { round cells }\end{array}$ & $\begin{array}{l}\text { At least focal } \\
\text { spindling }\end{array}$ & $\begin{array}{l}\text { Monotonous } \\
\text { round cells, } \\
\text { minimal } \\
\text { cytoplasm }\end{array}$ & $\begin{array}{l}\text { Monotonous } \\
\text { round cells, rare } \\
\text { multinucleated } \\
\text { giant cells or } \\
\text { striated cells }\end{array}$ & $\begin{array}{l}\text { Round cells and } \\
\text { spindled cells }\end{array}$ & $\begin{array}{l}\text { Round cells } \\
\text { with rare } \\
\text { univacuolated } \\
\text { lipoblasts }\end{array}$ \\
\hline Nuclear features & $\begin{array}{c}\text { Vesicular chromatin, } \\
\text { prominent nucleoli, } \\
\text { moderate } \\
\text { pleomorphism }\end{array}$ & $\begin{array}{c}\text { Fine chromatin, } \\
\text { inconspicuous } \\
\text { nucleoli }\end{array}$ & $\begin{array}{c}\text { Fine chromatin, } \\
\text { inconspicuous } \\
\text { nucleoli }\end{array}$ & $\begin{array}{l}\text { Vesicular } \\
\text { chromatin, } \\
\text { prominent } \\
\text { nucleoli }\end{array}$ & $\begin{array}{c}\text { Uniform } \\
\text { hyperchromasia, } \\
\text { inconspicuous } \\
\text { nucleoli, and } \\
\text { minimal } \\
\text { eosinophilic } \\
\text { cytoplasm }\end{array}$ & $\begin{array}{l}\text { Large, fine } \\
\text { chromatin, } \\
\text { prominent } \\
\text { nucleoli }\end{array}$ & $\begin{array}{c}\text { Small, fine } \\
\text { chromatin, } \\
\text { inconspicuous } \\
\text { nucleoli }\end{array}$ & $\begin{array}{c}\text { Vesicular } \\
\text { chromatin, } \\
\text { prominent } \\
\text { nucleoli, } \\
\text { moderate } \\
\text { pleomorphism }\end{array}$ \\
\hline Stroma & $\begin{array}{c}\text { Myxoid changes } \\
\text { common, subset } \\
\text { with dense hyaline } \\
\text { bands }\end{array}$ & $\begin{array}{l}\text { Subset with myxoid } \\
\text { changes }\end{array}$ & Scant & Scant & $\begin{array}{c}\text { Abundant } \\
\text { desmoplastic } \\
\text { stroma encasing } \\
\text { round cell nests }\end{array}$ & $\begin{array}{l}\text { Fibrotic septae } \\
\text { between } \\
\text { anastomosing } \\
\text { round cells }\end{array}$ & $\begin{array}{c}\text { Geographically } \\
\text { variable } \\
\text { chondroid } \\
\text { matrix }\end{array}$ & Myxoid changes \\
\hline $\begin{array}{c}\text { Typical positive } \\
\text { immunohistochemical } \\
\text { profile }\end{array}$ & $\begin{array}{c}\text { Patchy CD99, ETV4, } \\
\text { WT1, can be ERG } \\
\text { and FLI1 }\end{array}$ & $\begin{array}{c}\text { Patchy CD99, TLE1, } \\
\text { BCOR, } \\
\text { CCNB3 }\end{array}$ & $\begin{array}{c}\text { Diffuse } \\
\text { membranous } \\
\text { CD99, NKX2-2 }\end{array}$ & $\begin{array}{l}\text { TLE1, patchy } \\
\text { EMA and } \\
\text { keratin }\end{array}$ & $\begin{array}{l}\text { WT1, keratin, } \\
\text { EMA, desmin } \\
\text { (perinuclear) }\end{array}$ & $\begin{array}{l}\text { Desmin, } \\
\text { myogenin, } \\
\text { MyoD1 }\end{array}$ & $\begin{array}{c}\text { Diffuse } \\
\text { membranous } \\
\text { CD99, NKX2-2, } \\
\text { S100 in chondroid } \\
\text { areas }\end{array}$ & S100 \\
\hline $\begin{array}{l}\text { Genetics (in order } \\
\text { of incidence) }\end{array}$ & $\begin{array}{l}\text { CIC-DUX4, } \\
\text { CIC-DUX4L, } \\
\text { CIC-FOX04 }\end{array}$ & $\begin{array}{l}\text { BCOR-CCNB3, } \\
\text { BCOR-MAML3, } \\
\text { ZC3H7B-BCOR }\end{array}$ & $\begin{array}{c}\text { EWSR1-FLI1, } \\
\text { EWSR1-ERG, } \\
\text { EWSR1-PATZ1, } \\
\text { also FUS-ERG }\end{array}$ & $\begin{array}{l}\text { SS18-SSX1, } \\
\text { SS18-SSX2 }\end{array}$ & EWSR1-WT1 & $\begin{array}{l}\text { PAX3-FOX01, } \\
\text { PAX7-FOXO1 }\end{array}$ & HEY1-NCOA2 & $\begin{array}{c}\text { FUS-DDIT3 } \\
\text { EWSR1-DDIT3 }\end{array}$ \\
\hline
\end{tabular}


Recently, DUX4 immunostaining has been reported to be diffusely positive in all cases of CIC rearranged sarcomas evaluated (5/5 cases), but negative among other SBRCTs, including ES [49]. The present case was characterized by weakly focal CD99 immunoreactivity, and diffuse nuclear positivity for WT1, FLI1, and TLE1. Both morphology and immunohistochemistry (IHC) features prompted molecular testing, necessary to confirm the diagnosis [22].

However, as for our case, decision making might be complicated by false negative results in molecular testing of such tumors [12,16,31,37]. Recently, an overall low performance of break-apart FISH and total RNA sequencing as molecular tests for SBRCTs with CIC rearrangement was reported [12,25,50]. Indeed, complex alterations involving the CIC locus on chromosome $19 \mathrm{q}$, may have an adverse effect on FISH analysis [12]. Furthermore, automated algorithms for fusion discovery from RNA-Seq data could not detect the underlying gene fusion due to the highly repetitive DNA sequences juxtaposing the breakpoint in CIC [12]. In these cases, the underlying CIC-DUX4 fusion could only be detected by manually reviewing the reads of these genes [12]. While the revision of this manuscript was ongoing, we had the opportunity to further analyze the case by RNA-Seq. Finally, we detected the CIC-DUX4 rearrangement, thus confirming the results of the methylation profiling. In our case, RNA-Seq was able to detect the translocation but in the experience reported by Koelsche and colleagues it failed in three out of six CIC rearranged tumors [12].

Use of a surrogate marker could be a more viable approach for facilitating the diagnosis of SBRCTs. SBRCTs with CIC-DUX4 fusion have been shown to upregulate ETS transcription factors (ETV1 on chromosome 7p, ETV4 on chromosome 17q, ETV5 on chromosome 3q) $[39,43,47,50]$. RNA in situ hybridization performed on formalin-fixed paraffin-embedded tissues to detect ETV1, ETV4, and ETV5 transcripts was reported as a specific and sensitive ancillary test in cases with limited sample availability $[39,51]$. Recently, PAX7 was identified as highly differentially expressed between ES and CIC rearranged sarcoma, also at the protein level. Indeed, Charville et al. demonstrated that PAX7 expression evaluated by IHC was detectable in 102/103 ES and 0/27 CIC rearranged sarcomas [52].

Accurate pathologic diagnosis is essential to make optimal therapeutic choices for patients with cancer, avoiding both over- and under-treatment and allowing appropriate inclusion of patients in clinical trials. In recent years, genome-wide DNA methylation array analysis has allowed identification and characterization of episignatures for an increasing number of diseases $[53,54]$.

DNA methylation profiling has been shown to be a robust and reproducible approach for the classification of several tumor entities across age groups $[12,18,21,38,54]$. It takes advantage of the concept that the epigenetic signature in cancer is a combination of both somatically acquired DNA methylation changes and features that reflect the tumor cell origin in a lineage-dependent manner $[18,21,55]$. Epigenetic machinery regulates gene functions during developmental programs, tightly defined in space and time.

DNA methylation and histone modifications are among the most widely characterized epigenetic mechanisms of interest in these cases. CPG islands are variably distributed in the human genome; they are often located in gene promoters and act as key regulators of gene expression [56]. DNA methyltransferases catalyzes the covalent modification of the cytosine bases in CpG islands to generate 5-methylcytosine. This methylation makes DNA inaccessible to transcription factors and can also drive the formation of heterochromatin by histone modifiers.

In cancer, alteration in DNA methylation patterns can both transcriptionally inactivate tumor suppressors and increase oncogenes expression, sustaining tumorigenesis. Aberration in epigenetics can alter normal developmental programs and cell differentiation, leading to an uncontrolled proliferative state of progenitor cells [56]. Cytosine methylation at single-nucleotide resolution can be easily achieved by taking advantage of DNA bisulfite treatment. Such chemical process converts cytosine to uracil while not affecting 5-methylcytosine.

Array-based methods have progressively improved to reach over 850,000 CpG analyses throughout the human genome, such as the Illumina Infinium Human BeadChip arrays (450K and EPIC) that we used for our analysis [21,56]. These arrays have been shown to be rapid and cost-effective methods 
for genome-wide coverage of methylation patterns, providing critical insights into the epigenetic landscape of cancer [21,56]. They work comparably well on both formalin-fixed paraffin-embedded (FFPE) and frozen tumor samples from a relatively low DNA input (around 250 nanograms). Of note, these techniques show a rather short execution and analysis time (within a week), an appropriate timeframe for diagnostic implementation and use in the clinic.

Paralleling this technical progress, computational methods have been developed to deal the raw data in biologically and clinically applicable output $[12,21,56]$. These bioinformatics pipelines and classifiers use statistical tests and algorithms, such as random forest analyses, to make class predictions, exploiting advanced machine learning techniques. The main factor for the usefulness of DNA methylation profiling lies in the classification and clinical management of central nervous system tumors $[19,21]$.

This approach also has been shown to be useful for addressing undifferentiated SBRCTs not otherwise specified [12]. Koelsche and colleagues identified 30 tumors failing to exhibit the typical ES translocation in a cohort of more than 1000 tumors considered as Ewing sarcomas. The authors performed tumor methylation profiling and analyzed data by unsupervised clustering and $\mathrm{t}$-distributed stochastic neighbor embedding analysis, comparing with a reference methylation data set of 460 well-characterized prototypical sarcomas containing 18 subtypes. Tumors were assigned to Ewing sarcoma in $14(47 \%)$, to SBRCTs with CIC alteration in $6(20 \%)$, to SBRCTs with BCOR alterations in 4 $(13 \%)$, to synovial sarcoma and to malignant rhabdoid tumors in 2 cases each, 1 case to mesenchymal chondrosarcoma, and 1 to adamantinoma. For cases assigned to the SBRCTs with CIC alterations, methylation class was verified by additional FISH and total RNA sequencing. Four of the six tumors revealed a CIC break-apart signal in the FISH analysis, indicating a rearrangement of the CIC locus. In two of them, RNA sequencing analysis detected a CIC-DUX4 fusion. RNA sequencing also revealed a CIC-DUX4 fusion in one of the two cases without a CIC break-apart signal [12].

This breakthrough tool has allowed us to successfully address a challenging diagnosis. Overall, DNA methylation profiling could have clinical implications in the molecular diagnostics of SBRCT, as already documented in central nervous system tumors [21,38].

\section{Conclusion}

CIC rearranged sarcomas are rare tumors that present substantial diagnostic challenges; morphological diagnosis is difficult. Since the immunohistochemical expression pattern seen in these tumors is unique, this is a useful adjunct in orienting a pathologic definition. Molecular testing is necessary to confirm diagnosis, but FISH and total RNA sequencing may sometimes have pitfalls.

In our view, DNA methylation profiles represent a highly useful instrument in the diagnosis and the molecular characterization of SBRCTs, with potential application in almost all pathology fields.

Supplementary Materials: Supplementary materials can be found at http://www.mdpi.com/1422-0067/21/5/1818/ s1.

Author Contributions: E.M.: conception (ideation), design of the work, structuration, interpretation of the data, writing; R.D.V.: pathological findings; A.C. (Andrea Ciolfi): data analysis, revision; L.P.: acquisition of the data, revision; I.R., A.D.G., M.D.D.P., and G.M.M.: patient management, revision; A.C. (Alessandro Crocoli): surgery, revision; B.D.A.: RNA sequencing studies; M.T., R.A., and G.M.M.: supervision and critical revision for intellectual content. All authors have read and agreed to the published version of the manuscript.

Funding: This work was supported by Ricerca Corrente (Italian Ministry of Health) to EM.

Acknowledgments: We thank Claudia Nardini for providing excellent technical support. We thank William Marc Silberg from the Department of Surgery, IRCCS Bambino Gesù Children's Hospital for providing writing support.

Ethics Statement: This study was carried out in accordance with the recommendations of the Internal Review Board of the Bambino Gesù Ospedale Pediatrico with written informed consent from the subject. Patient' parents gave written informed consent in accordance with the Declaration of Helsinki.

Informed Consent: The authors declare that written informed consent was obtained from the patient's parents for publication of this case report.

Conflicts of Interest: The authors declare no conflicts of interest. 


\section{References}

1. Renzi, S.; Anderson, N.D.; Light, N.; Gupta, A. Ewing-like sarcoma: An emerging family of round cell sarcomas. J. Cell Physiol. 2019, 234, 7999-8007. [CrossRef] [PubMed]

2. Carter, C.S.; Patel, R.M. Important Recently Characterized Non-Ewing Small Round Cell Tumors. Surg. Pathol. Clin. 2019, 12, 191-215. [CrossRef] [PubMed]

3. Delattre, O.; Zucman, J.; Plougastel, B.; Desmaze, C.; Melot, T.; Peter, M.; Kovar, H.; Joubert, I.; de Jong, P.; Rouleau, G.; et al. Gene fusion with an ETS DNA-binding domain caused by chromosome translocation in human tumours. Nature 1992, 359, 162-165. [CrossRef]

4. Sorensen, P.H.B.; Lessnick, S.L.; Lopez-Terrada, D.; Liu, X.F.; Triche, T.J.; Denny, C.T. A second Ewing's sarcoma translocation, $\mathrm{t}(21 ; 22)$, fuses the EWS gene to another ETS-family transcription factor, ERG. Nat. Genet. 1994, 6, 146-151. [CrossRef] [PubMed]

5. Szuhai, K.; IJszenga, M.; de Jong, D.; Karseladze, A.; Tanke, H.J.; Hogendoorn, P.C.W. The NFATc2 Gene Is Involved in a Novel Cloned Translocation in a Ewing Sarcoma Variant That Couples Its Function in Immunology to Oncology. Clin. Cancer Res. 2009, 15, 2259-2268. [CrossRef] [PubMed]

6. Sumegi, J.; Nishio, J.; Nelson, M.; Frayer, R.W.; Perry, D.; Bridge, J.A. A novel t(4;22)(q31;q12) produces an EWSR1-SMARCA5 fusion in extraskeletal Ewing sarcoma/primitive neuroectodermal tumor. Mod. Pathol. 2011, 24, 333-342. [CrossRef]

7. Llombart-Bosch, A.; Machado, I.; Navarro, S.; Bertoni, F.; Bacchini, P.; Alberghini, M.; Karzeladze, A.; Savelov, N.; Petrov, S.; Alvarado-Cabrero, I.; et al. Histological heterogeneity of Ewing's sarcoma/PNET: An immunohistochemical analysis of 415 genetically confirmed cases with clinical support. Virchows Arch. 2009, 455, 397-411. [CrossRef]

8. Mastrangelo, T.; Modena, P.; Tornielli, S.; Bullrich, F.; Testi, M.A.; Mezzelani, A.; Radice, P.; Azzarelli, A.; Pilotti, S.; Croce, C.M.; et al. A novel zinc finger gene is fused to EWS in small round cell tumor. Oncogene 2000, 19, 3799-3804. [CrossRef]

9. Wang, L.; Bhargava, R.; Zheng, T.; Wexler, L.; Collins, M.H.; Roulston, D.; Ladanyi, M. Undifferentiated Small Round Cell Sarcomas with Rare EWS Gene Fusions. J. Mol. Diagn. 2007, 9, 498-509. [CrossRef]

10. Watson, S.; Perrin, V.; Guillemot, D.; Reynaud, S.; Coindre, J.-M.; Karanian, M.; Guinebretière, J.-M.; Freneaux, P.; Le Loarer, F.; Bouvet, M.; et al. Transcriptomic definition of molecular subgroups of small round cell sarcomas: Molecular classification of sarcoma subtypes. J. Pathol. 2018, 245, 29-40. [CrossRef]

11. Jo, V.Y.; Fletcher, C.D.M. WHO classification of soft tissue tumours: An update based on the 2013 (4th) edition. Pathology 2014, 46, 95-104. [CrossRef]

12. Koelsche, C.; Hartmann, W.; Schrimpf, D.; Stichel, D.; Jabar, S.; Ranft, A.; Reuss, D.E.; Sahm, F.; Jones, D.T.W.; Bewerunge-Hudler, M.; et al. Array-based DNA-methylation profiling in sarcomas with small blue round cell histology provides valuable diagnostic information. Mod. Pathol. 2018, 31, 1246-1256. [CrossRef] [PubMed]

13. Alaggio, R.; Coffin, C.M. The Evolution of Pediatric Soft Tissue Sarcoma Classification in the Last 50 Years. Pediatr. Dev. Pathol. 2015, 18, 481-494. [CrossRef] [PubMed]

14. Kawamura-Saito, M.; Yamazaki, Y.; Kaneko, K.; Kawaguchi, N.; Kanda, H.; Mukai, H.; Gotoh, T.; Motoi, T.; Fukayama, M.; Aburatani, H.; et al. Fusion between CIC and DUX4 up-regulates PEA3 family genes in Ewing-like sarcomas with $\mathrm{t}(4 ; 19)(\mathrm{q} 35 ; \mathrm{q} 13)$ translocation. Human Mol. Genet. 2006, 15, 2125-2137. [CrossRef] [PubMed]

15. Pierron, G.; Tirode, F.; Lucchesi, C.; Reynaud, S.; Ballet, S.; Cohen-Gogo, S.; Perrin, V.; Coindre, J.-M.; Delattre, O. A new subtype of bone sarcoma defined by BCOR-CCNB3 gene fusion. Nat. Genet. 2012, 44, 461-466. [CrossRef] [PubMed]

16. Italiano, A.; Sung, Y.S.; Zhang, L.; Singer, S.; Maki, R.G.; Coindre, J.-M.; Antonescu, C.R. High prevalence of CIC fusion with double-homeobox (DUX4) transcription factors in EWSR1-negative undifferentiated small blue round cell sarcomas. Genes Chromosom. Cancer 2012, 51, 207-218. [CrossRef]

17. Specht, K.; Zhang, L.; Sung, Y.-S.; Nucci, M.; Dry, S.; Vaiyapuri, S.; Richter, G.H.S.; Fletcher, C.D.M.; Antonescu, C.R. Novel BCOR-MAML3 and ZC3H7B-BCOR Gene Fusions in Undifferentiated Small Blue Round Cell Sarcomas. Am. J. Surg. Pathol. 2016, 40, 433-442. [CrossRef] [PubMed]

18. Petruzzellis, G.; Alessi, I.; Colafati, G.S.; Diomedi-Camassei, F.; Ciolfi, A.; Pedace, L.; Cacchione, A.; Carai, A.; Tartaglia, M.; Mastronuzzi, A.; et al. Role of DNA Methylation Profile in Diagnosing Astroblastoma: A Case Report and Literature Review. Front. Genet. 2019, 10, 391. [CrossRef] 
19. Flex, E.; Martinelli, S.; Van Dijck, A.; Ciolfi, A.; Cecchetti, S.; Coluzzi, E.; Pannone, L.; Andreoli, C.; Radio, F.C.; Pizzi, S.; et al. Aberrant Function of the C-Terminal Tail of HIST1H1E Accelerates Cellular Senescence and Causes Premature Aging. Am. J. Hum. Genet. 2019, 105, 493-508. [CrossRef]

20. Ballabio, C.; Anderle, M.; Gianesello, M.; Lago, C.; Miele, E.; Cardano, M.; Aiello, G.; Piazza, S.; Caron, D.; Gianno, F.; et al. Modeling Medulloblastoma in-vivo and with human cerebellar organoids. Nature Commun. 2019. [CrossRef]

21. Capper, D.; Jones, D.T.W.; Sill, M.; Hovestadt, V.; Schrimpf, D.; Sturm, D.; Koelsche, C.; Sahm, F.; Chavez, L.; Reuss, D.E.; et al. DNA methylation-based classification of central nervous system tumours. Nature 2018, 555, 469-474. [CrossRef] [PubMed]

22. Le Loarer, F.; Pissaloux, D.; Coindre, J.M.; Tirode, F.; Vince, D.R. Update on Families of Round Cell Sarcomas Other than Classical Ewing Sarcomas. Surg. Pathol. Clin. 2017, 10, 587-620. [CrossRef] [PubMed]

23. Machado, I.; Navarro, S.; Llombart-Bosch, A. Ewing sarcoma and the new emerging Ewing-like sarcomas: (CIC and BCOR-rearranged-sarcomas). A systematic review. Histol. Histopathol. 2016, 31, 1169-1181. [PubMed]

24. Graham, C.; Chilton-MacNeill, S.; Zielenska, M.; Somers, G.R. The CIC-DUX4 fusion transcript is present in a subgroup of pediatric primitive round cell sarcomas. Hum. Pathol. 2012, 43, 180-189. [CrossRef]

25. Yoshida, A.; Goto, K.; Kodaira, M.; Kobayashi, E.; Kawamoto, H.; Mori, T.; Yoshimoto, S.; Endo, O.; Kodama, N.; Kushima, R.; et al. CIC-rearranged Sarcomas: A Study of 20 Cases and Comparisons With Ewing Sarcomas. Am. J. Surg. Pathol. 2016, 40, 313-323. [CrossRef]

26. Kilpatrick, S.E.; Reith, J.D.; Rubin, B. Ewing Sarcoma and the History of Similar and Possibly Related Small Round Cell Tumors: From Whence Have We Come and Where are We Going? Adv. Anat. Pathol. 2018, 25, 314-326. [CrossRef]

27. Richkind, K.E.; Romansky, S.G.; Finklestein, J.Z. t(4;19)(q35;q13.1): A recurrent change in primitive mesenchymal tumors? Cancer Genet. Cytogenet. 1996, 87, 71-74. [CrossRef]

28. Van Geel, M.; van Deutekom, J.C.T.; van Staalduinen, A.; Lemmers, R.J.L.F.; Dickson, M.C.; Hofker, M.H.; Padberg, G.W.; Hewitt, J.E.; de Jong, P.J.; Frants, R.R. Identification of a novel $\beta$-tubulin subfamily with one member (TUBB4Q) located near the telomere of chromosome region 4q35. Cytogenet. Genome Res. 2000, 88, 316-321. [CrossRef]

29. Van der Maarel, S.M.; Tawil, R.; Tapscott, S.J. Facioscapulohumeral muscular dystrophy and DUX4: Breaking the silence. Trends Mol. Med. 2011, 17, 252-258. [CrossRef]

30. Krom, Y.D.; Thijssen, P.E.; Young, J.M.; den Hamer, B.; Balog, J.; Yao, Z.; Maves, L.; Snider, L.; Knopp, P.; Zammit, P.S.; et al. Intrinsic Epigenetic Regulation of the D4Z4 Macrosatellite Repeat in a Transgenic Mouse Model for FSHD. PLoS Genet. 2013, 9, e1003415. [CrossRef]

31. Antonescu, C.R.; Owosho, A.A.; Zhang, L.; Chen, S.; Deniz, K.; Huryn, J.M.; Kao, Y.-C.; Huang, S.-C.; Singer, S.; Tap, W.; et al. Sarcomas with CIC-rearrangements Are a Distinct Pathologic Entity with Aggressive Outcome: A Clinicopathologic and Molecular Study of 115 Cases. Am. J. Surg. Pathol. 2017, 41, 941-949. [CrossRef] [PubMed]

32. Choi, E.-Y.K.; Thomas, D.G.; McHugh, J.B.; Patel, R.M.; Roulston, D.; Schuetze, S.M.; Chugh, R.; Biermann, J.S.; Lucas, D.R. Undifferentiated Small Round Cell Sarcoma with t(4;19)(q35;q13.1) CIC-DUX4 Fusion: A Novel Highly Aggressive Soft Tissue Tumor with Distinctive Histopathology. Am. J. Surg. Pathol. 2013, 37, 1379-1386. [CrossRef] [PubMed]

33. Yoshimoto, T.; Tanaka, M.; Homme, M.; Yamazaki, Y.; Takazawa, Y.; Antonescu, C.R.; Nakamura, T. CIC-DUX4 Induces Small Round Cell Sarcomas Distinct from Ewing Sarcoma. Cancer Res. 2017, 77, 2927-2937. [CrossRef] [PubMed]

34. Jeon, I.S.; Davis, J.N.; Braun, B.S.; Sublett, J.E.; Roussel, M.F.; Denny, C.T.; Shapiro, D.N. A variant Ewing's sarcoma translocation (7;22) fuses the EWS gene to the ETS gene ETV1. Oncogene 1995, 10, 1229-1234.

35. Kaneko, Y.; Yoshida, K.; Handa, M.; Toyoda, Y.; Nishihira, H.; Tanaka, Y.; Sasaki, Y.; Ishida, S.; Higashino, F.; Fujinaga, K. Fusion of an ETS-family gene, EIAF, to EWS by $\mathrm{t}(17 ; 22)(\mathrm{q} 12 ; \mathrm{q} 12)$ chromosome translocation in an undifferentiated sarcoma of infancy. Genes Chromosomes Cancer 1996, 15, 115-121. [CrossRef]

36. Solomon, D.A.; Brohl, A.S.; Khan, J.; Miettinen, M. Clinicopathologic Features of a Second Patient with Ewing-like Sarcoma Harboring CIC-FOXO4 Gene Fusion. Am. J. Surg. Pathol. 2014, 38, 1724-1725. [CrossRef] 
37. Sugita, S.; Arai, Y.; Tonooka, A.; Hama, N.; Totoki, Y.; Fujii, T.; Aoyama, T.; Asanuma, H.; Tsukahara, T.; Kaya, M.; et al. A Novel CIC-FOXO4 Gene Fusion in Undifferentiated Small Round Cell Sarcoma: A Genetically Distinct Variant of Ewing-like Sarcoma. Am. J. Surg. Pathol. 2014, 38, 1571-1576. [CrossRef]

38. Sturm, D.; Orr, B.A.; Toprak, U.H.; Hovestadt, V.; Jones, D.T.W.; Capper, D.; Sill, M.; Buchhalter, I.; Northcott, P.A.; Leis, I.; et al. New Brain Tumor Entities Emerge from Molecular Classification of CNS-PNETs. Cell 2016, 164, 1060-1072. [CrossRef]

39. Smith, S.C.; Palanisamy, N.; Martin, E.; Almenara, J.; McHugh, J.B.; Choi, E.-Y.K.; Lucas, D.R.; Betz, B.L.; Thomas, D.; Patel, R.M. The utility of ETV1, ETV4 and ETV5 RNA in-situ hybridization in the diagnosis of CIC-DUX sarcomas. Histopathology 2017, 70, 657-663. [CrossRef]

40. Gambarotti, M.; Benini, S.; Gamberi, G.; Cocchi, S.; Palmerini, E.; Sbaraglia, M.; Donati, D.; Picci, P.; Vanel, D.; Ferrari, S.; et al. CIC-DUX4 fusion-positive round-cell sarcomas of soft tissue and bone: A single-institution morphological and molecular analysis of seven cases. Histopathology 2016, 69, 624-634. [CrossRef]

41. Haidar, A.; Arekapudi, S.; DeMattia, F.; Abu-Isa, E.; Kraut, M. High-grade undifferentiated small round cell sarcoma with $\mathrm{t}(4 ; 19)$ (q35;q13.1) CIC-DUX4 fusion: Emerging entities of soft tissue tumors with unique histopathologic features-a case report and literature review. Am. J. Case Rep. 2015, 16, 87-94. [PubMed]

42. Pappo, A.S.; Dirksen, U. Rhabdomyosarcoma, Ewing Sarcoma, and Other Round Cell Sarcomas. JCO 2018, 36, 168-179. [CrossRef] [PubMed]

43. Specht, K.; Sung, Y.-S.; Zhang, L.; Richter, G.H.S.; Fletcher, C.D.; Antonescu, C.R. Distinct transcriptional signature and immunoprofile of CIC-DUX4 fusion-positive round cell tumors compared to EWSR1 -rearranged ewing sarcomas: Further evidence toward distinct pathologic entities: Gene Expression in CIC-DUX4 Sarcomas. Genes Chromosomes Cancer 2014, 53, 622-633. [CrossRef] [PubMed]

44. Yamada, Y.; Kuda, M.; Kohashi, K.; Yamamoto, H.; Takemoto, J.; Ishii, T.; Iura, K.; Maekawa, A.; Bekki, H.; Ito, T.; et al. Histological and immunohistochemical characteristics of undifferentiated small round cell sarcomas associated with CIC-DUX4 and BCOR-CCNB3 fusion genes. Virchows Arch. 2017, 470, 373-380. [CrossRef] [PubMed]

45. Smith, S.C.; Buehler, D.; Choi, E.-Y.K.; McHugh, J.B.; Rubin, B.P.; Billings, S.D.; Balzer, B.; Thomas, D.G.; Lucas, D.R.; Goldblum, J.R.; et al. CIC-DUX sarcomas demonstrate frequent MYC amplification and ETS-family transcription factor expression. Mod. Pathol. 2015, 28, 57-68. [CrossRef] [PubMed]

46. Hung, Y.P.; Fletcher, C.D.; Hornick, J.L. Evaluation of ETV4 and WT1 expression in CIC-rearranged sarcomas and histologic mimics. Mod. Pathol. 2016, 29, 1324-1334. [CrossRef] [PubMed]

47. Le Guellec, S.; Velasco, V.; Pérot, G.; Watson, S.; Tirode, F.; Coindre, J.-M. ETV4 is a useful marker for the diagnosis of CIC-rearranged undifferentiated round-cell sarcomas: A study of 127 cases including mimicking lesions. Mod. Pathol. 2016, 29, 1523-1531. [CrossRef]

48. Hung, Y.P.; Fletcher, C.D.M.; Hornick, J.L. Evaluation of NKX2-2 expression in round cell sarcomas and other tumors with EWSR1 rearrangement: Imperfect specificity for Ewing sarcoma. Mod. Pathol. 2016, 29, 370-380. [CrossRef]

49. Siegele, B.; Roberts, J.; Black, J.O.; Rudzinski, E.; Vargas, S.O.; Galambos, C. DUX4 Immunohistochemistry Is a Highly Sensitive and Specific Marker for CIC-DUX4 Fusion-positive Round Cell Tumor. Am. J. Surg. Pathol. 2017, 41, 423-429. [CrossRef]

50. Kao, Y.-C.; Sung, Y.-S.; Chen, C.-L.; Zhang, L.; Dickson, B.C.; Swanson, D.; Vaiyapuri, S.; Latif, F.; Alholle, A.; Huang, S.-C.; et al. ETV transcriptional upregulation is more reliable than RNA sequencing algorithms and FISH in diagnosing round cell sarcomas with CIC gene rearrangements: Kao et al. Genes Chromosomes Cancer 2017, 56, 501-510. [CrossRef]

51. Kunju, L.P.; Carskadon, S.; Siddiqui, J.; Tomlins, S.A.; Chinnaiyan, A.M.; Palanisamy, N. Novel RNA Hybridization Method for the In Situ Detection of ETV1, ETV4, and ETV5 Gene Fusions in Prostate Cancer. Appl. Immunohistochem. Mol. Morphol. 2014, 22, e32-e40. [CrossRef] [PubMed]

52. Charville, G.W.; Wang, W.-L.; Ingram, D.R.; Roy, A.; Thomas, D.; Patel, R.M.; Hornick, J.L.; van de Rijn, M.; Lazar, A.J. EWSR1 fusion proteins mediate PAX7 expression in Ewing sarcoma. Mod. Pathol. 2017, 30, 1312-1320. [CrossRef] [PubMed]

53. Ciolfi, A.; Aref-Eshghi, E.; Pizzi, S.; Pedace, L.; Miele, E.; Kerkhof, J.; Flex, E.; Martinelli, S.; Radio, F.C.; Ruivenkamp, C.A.L.; et al. Frameshift mutations at the C-terminus of HIST1H1E result in a specific DNA hypomethylation signature. Clin. Epigenet. 2020, 12, 7. [CrossRef] [PubMed] 
54. Renner, M.; Wolf, T.; Meyer, H.; Hartmann, W.; Penzel, R.; Ulrich, A.; Lehner, B.; Hovestadt, V.; Czwan, E.; Egerer, G.; et al. Integrative DNA methylation and gene expression analysis in high-grade soft tissue sarcomas. Genome. Biol. 2013, 14, r137. [CrossRef] [PubMed]

55. Heyn, H.; Esteller, M. DNA methylation profiling in the clinic: Applications and challenges. Nat. Rev. Genet. 2012, 13, 679-692. [CrossRef]

56. Kumar, R.; Liu, A.P.Y.; Orr, B.A.; Northcott, P.A.; Robinson, G.W. Advances in the classification of pediatric brain tumors through DNA methylation profiling: From research tool to frontline diagnostic: Classification of Pediatric Brain Tumors. Cancer 2018, 124, 4168-4180. [CrossRef]

(C) 2020 by the authors. Licensee MDPI, Basel, Switzerland. This article is an open access article distributed under the terms and conditions of the Creative Commons Attribution (CC BY) license (http://creativecommons.org/licenses/by/4.0/). 